\title{
ASSISTÊNCIA ESTUDANTIL E DEMANDAS DE ATENDIMENTO EM SAÚDE: construções do Serviço Social no IFFluminense*
}

\author{
Josemara Henrique da Silva Pessanha \\ Amanda Bersacula de Azevedo \\ Lenon Araújo de Matos
}

\section{Introdução}

A atuação do/a assistente social na política de educação, embora não seja uma novidade, vem suscitando novas discussões teórico-práticas, muitas reflexões da categoria e representa um enorme desafio para a formação e para o trabalho profissional. Nas últimas duas décadas, foi possível observar um aumento no quantitativo de profissionais atuando na política de educação, seja no âmbito das ações de Ensino Básico, de nível fundamental, médio ou profissionalizante, seja no âmbito do ensino superior (PRADA, 2015; PRADA; GARCIA, 2017).

Com a expansão das Universidades e Institutos Federais por meio do REUNI Reestruturação e Expansão das Universidades Federais e Plano de Expansão da Rede Federal de Educação Tecnológica, respectivamente ${ }^{1}$, a implementação de políticas de ações afirmativas de acesso $^{2}$, e a consolidação da política de permanência com incremento orçamentário referendadas na Política Nacional de Assistência Estudantil ${ }^{3}$, há um aumento de profissionais de Serviço Social atuando na política pública de educação nas redes federais de ensino.

Em relação às discussões e reflexões da categoria sobre a atuação profissional nesse âmbito, destaca-se o esforço do conjunto CFESS-CRESS e de coletivos representantes da categoria profissional de organizar o debate acerca desse assunto, que culminou na publicação dos "Subsídios para Atuação do Assistente Social na Política de Educação" (CFESS, 2012). Conforme esse documento, o trabalho do/a assistente social na política de educação

[...] não se restringe ao segmento estudantil e nem às abordagens individuais. Envolve também ações junto às famílias, aos professores e professoras, aos demais trabalhadores e trabalhadoras da educação, aos gestores e gestoras dos estabelecimentos públicos e privados, aos/às profissionais e às redes que compõem as demais políticas sociais, às instâncias de controle social e aos movimentos sociais, ou seja, ações não só de caráter individual, mas também coletivo, administrativo-organizacional, de investigação, de articulação, de formação e capacitação profissional (CFESS, 2012, p. 38).

Observa-se que a atuação profissional no âmbito da Política de Educação revela uma abrangência de ações e uma diversificação dos sujeitos da intervenção, dos instrumentos e

${ }^{*}$ DOI- 10.29388/978-65-81417-27-7-0-f.176-188

1 O Reuni foi instituído pelo Decreto ${ }^{\circ}$ 6.096, de 24 de abril de 2007 e o processo de expansão das instituições federais de educação profissional e tecnológica por meio da Lei n ${ }^{\circ} 11.195$, de 18 de Novembro de 2005 revogou a lei que proibia a expansão das unidades.

${ }^{2}$ Lei n ${ }^{\circ}$ 12.711, de 29 de 2012 que Dispõe sobre o ingresso nas universidades federais e nas instituições federais de ensino técnico de nível médio e dá outras providências.

${ }^{3}$ Decreto n 7.234, de 19 de julho de 2010 que Dispõe sobre o Programa Nacional de Assistência Estudantil - PNAES. 
técnicas e do alcance, que pode ser individual ou coletivo. Embora a requisição institucional ao/a assistente social seja o atendimento ao estudante por meio do Programa de Assistência Estudantil, há inúmeras faces desse trabalho, diversas demandas que emergem do público atendido e outro tanto de estratégias profissionais que buscam concretizar o projeto éticopolítico profissional nessa política.

A pesquisa de Abreu $(2017 ; 2018)$, que identifica a ampliação das dimensões do trabalho e requisições para o/a assistente social que atuam nos Institutos Federais, aponta os diversificados aspectos do trabalho em quatro eixos principais: 1) referente à assistência estudantil; 2) de caráter sócio-educativo; 3) de orientação, acompanhamento e encaminhamento de estudantes; e 4) de assessoria às organizações estudantis e de pais. Esses quatro eixos e seus desdobramentos indicam a existência do que se pode chamar de "especificidade abrangente" no trabalho do/a assistente social.

No trabalho do/a Assistente Social do IFFluminense também é possível identificar essa "especificidade abrangente". Mesmo atuando no Programa de Assistência Estudantil e/ou setores de atendimento ao estudante, o/a profissional recebe e/ou identifica outras demandas de atuação. Nesse sentido, o presente capítulo tem por objetivo apresentar a pesquisa realizada com assistentes sociais do IFFluminense no que se refere às demandas de atendimento em saúde apresentadas pelos estudantes e elaborar algumas reflexões sobre os limites e as possibilidades de trabalho a partir da manifestação dessas demandas na política de educação.

O capítulo apresenta uma breve contextualização sobre a instituição em que esses profissionais atuam, as nuances que a inserção de cada profissional adquire conforme o seu campus e setor de atuação, as maneiras como a demanda de atendimento em saúde se manifesta e as respostas e encaminhamentos dados a essas demandas, tendo em vista a sua atuação em uma instituição de educação. Apresentam-se também os dados coletados e sistematizados pelos profissionais em relação às demandas de atendimento em saúde dos estudantes e, por fim, as reflexões inferidas acerca das possibilidades e dos limites de atuação profissional nesse âmbito.

\section{IFFluminense, as particularidades da Assistência Estudantil e o/a assistente social}

O Instituto Federal de Educação, Ciência e Tecnologia Fluminense (IFFluminense) é uma instituição vinculada a Rede Federal de Educação Profissional e Tecnológica que está organizada pedagogicamente para ofertar cursos de diferentes níveis e modalidades de ensino, da educação básica ao ensino superior.

Essa característica está pautada no seu perfil institucional, nos princípios e fundamentos, em sua missão comprometida em contribuir com o desenvolvimento socioeconômico, cultural, científico e tecnológico, se propondo a combater as desigualdades sociais, buscando oferecer uma formação educacional humana, de qualidade e cidadã.

A proposta educacional dos IFs com o compromisso de unir a construção de conhecimentos à transformação da sociedade a partir da educação profissional e tecnológica (EPT) trouxe um caráter inovador decorrente das especificidades de sua identidade institucional, caracterizada pela expansão territorial, pela estrutura multicampi e a clara definição do território de abrangência das ações, pela organização pedagógica verticalizada, a partir da educação básica, passando da formação inicial e continuada até os níveis superiores (PDI 20182022, 2018, p. 56). 
Atualmente, o IFFluminense conta com unidades administrativas, como: a Reitoria, o Centro de Referência em Educação, Ciência e tecnologia, o Pólo de Inovação e 11 campi em funcionamento situados em municípios do estado do Rio de Janeiro, compreendendo sua abrangência nas Regiões Norte, Noroeste e Baixadas Litorâneas Fluminense.

A partir dessa expansão no território e estrutura multicampi, o IFFluminense atende um total de 22.924 estudantes matriculados nos diferentes cursos oferecidos institucionalmente. Desses, 6.744 estudantes estão matriculados em cursos de Formação Inicial e Continuada - FIC, 10.031 no ensino técnico (concomitante, integrado e subseqüente), outros 5.808 frequentam o ensino superior (bacharelado, licenciatura, tecnólogo) e 341 cursam a pós-graduação (especialização, mestrado e doutorado) ${ }^{4}$.

É neste contexto que se desenvolve o trabalho do/a assistente social no IFFluminense. O público atendido que compõe a comunidade escolar se configura num perfil dinâmico e heterogêneo, com particularidades que se apresentam no cotidiano profissional, via demandas e necessidades, considerando as contradições e mazelas da estrutura social vigente no país.

Pode-se dizer que o trabalho do/a assistente social no IFFluminense se apresenta em formato multifacetado. Prioritariamente, estes/as profissionais atuam em equipes multidisciplinares constituídas nos setores dos diferentes campi, porém, seus procedimentos teórico-metodológicos, técnico-instrumentais e ético-políticos podem se estender por diversas áreas e serviços.

Compreende-se que os aspectos mencionados podem se articular entre si até de forma inconsciente pelo/a assistente social, entretanto sinalizam um movimento profissional com o objetivo principal de garantir o direito à educação, a gestão democrática e a qualidade da educação.

Tradicionalmente o/a assistente social é chamado a atuar no Programa de Assistência Estudantil, especificamente, nos processos seletivos de concessão de benefícios e em ações que minimizem as possibilidades de evasão e abandono escolar. No IFFluminense, essa realidade não é diferente. Com a redução orçamentária nos últimos anos na política de Assistência Estudantil e o crescente empobrecimento da população, essas ações requerem maior seletividade e, ao mesmo tempo revelam outras demandas.

O Decreto n. 7.234 de 19 de julho de 2010 versa sobre o Programa Nacional de Assistência Estudantil - PNAES. Esta legislação fundamenta o planejamento de diferentes ações nas Instituições públicas a nível federal, tanto nos Institutos quanto nas Universidades e, em ambas, o/a assistente social é convocado/a a atuar, executar e conduzir sua implementação.

A assistência estudantil nos Institutos Federais envolve uma gama de ações e serviços que primam pelo acesso, permanência e êxito dos estudantes no ambiente escolar/acadêmico na tentativa de minimizar as dificuldades oriundas de condições socioeconômicas desfavoráveis e vulnerabilidades sociais que afetam o corpo discente.

De acordo com Abreu (2018, p. 3),

[...] as demandas postas por esses estudantes e suas famílias ao Serviço Social em relação à assistência estudantil tratam especificamente da falta de condições financeiras para garantir o transporte, a alimentação, a moradia, saúde, material didático escolar, entre outras situações relacionadas à garantia do direito à

${ }^{4}$ Dados coletados a partir de consulta realizada no site: iffemnumeros.iff.edu.br em 03 de junho de 2021. 
educação agravada pelo aumento do desemprego e das demais formas de precarização do trabalho.

No cotidiano profissional, o/a assistente social se envolve diretamente com as demandas estudantis buscando acolher e formular respostas para minimizar os problemas apresentados.

Em seu Art. $3^{\circ}$, o PNAES prevê que as ações devem ser articuladas com as atividades de ensino, pesquisa e extensão, visando o atendimento de estudantes regularmente matriculados em cursos presenciais das instituições federais.

As áreas de atendimento da assistência estudantil no PNAES deverão incluir: I - moradia estudantil; II - alimentação; III - transporte; IV - atenção à saúde; V - inclusão digital; VI cultura; VII - esporte; VIII - creche; IX - apoio pedagógico; e X - acesso, participação e aprendizagem de estudantes com deficiência, transtornos globais do desenvolvimento e altas habilidades e superdotação.

No IFFluminense, a Política de Assistência Estudantil prevista na Resolução n. ${ }^{\circ} 39$ de 10 de março de 2016, sinaliza a importância da atuação nessas áreas e propõe

[...] parâmetros nos quais os diversos campi deverão se basear para atender às demandas existentes, sem perder de vista, porém, a possibilidade de adequação dos recursos, da amplitude e dinâmica de execução das ações e projetos à realidade social, acadêmica e econômica dos estudantes e da região na qual o campus está localizado (IFFLUMINENSE, 2016, p. 4).

Entretanto, quando nos debruçamos para investigar o atendimento do/a assistente social na área de atenção à saúde do estudante, foi identificada a necessidade de sistematizar os dados levantados na pesquisa e direcionar o olhar para a questão que é o foco de análise nesse capítulo.

Primeiramente, ao iniciar o levantamento de documentos sobre o trabalho do/a assistente social no IFFluminense, tanto na área da Assistência Estudantil quanto em outras frentes de atuação, não foi identificado um projeto de intervenção específico na área de atenção à saúde.

De acordo com o Plano de Desenvolvimento Institucional do IFFLuminense (20182022, p. 248), está previsto a construção da Política de Atenção à Saúde dos Discentes do IFFluminense, elaborada a partir de uma visão ampliada de saúde compreendendo-a não como simples ausência de doença, mas como um processo relacionado à promoção da saúde, prevenção de doenças, atenção à qualidade de vida dos sujeitos e acesso aos demais direitos sociais, cujo principal objetivo é promover uma atenção ao discente como um "ser integral", viabilizando sua permanência no Instituto.

A construção da Política de Atenção à Saúde dos Discentes do IFFluminense vai ao encontro para atender necessidades sociais e de saúde partindo do pressuposto que a realidade estudantil nessa área carece de atendimento na Rede Pública de Saúde (SUS), considerando que a própria localização dos campi do IFFluminense são em áreas em que a população encontra obstáculos para garantir seus direitos, tanto na educação quanto na saúde.

De acordo com dados da pesquisa do FONAPRACE (2019), sobre o Perfil Socioeconômico e Cultural dos(as) Graduandos(as) das IFES, destacam-se os seguintes índices a respeito da saúde discente: 
- $21,2 \%$ dos estudantes que pensaram em abandonar seus respectivos cursos justificaram que o principal motivo seria por problemas de saúde;

- $\quad 53,6 \%$ informaram que são atendidos pelo SUS;

- $32,4 \%$ dos estudantes estiveram ou estavam em atendimento psicológico;

- $\quad 83,5 \%$ dos estudantes possuem dificuldades emocionais que interferem em sua vida acadêmica.

Apesar dos percentuais apresentados se tratarem da realidade de estudantes de graduação das Instituições Federais de Ensino, pode-se hipoteticamente suspeitar que esses números se aproximam da realidade do corpo discente do IFFluminense.

Na perspectiva de Carvalho, Barreto e Rodrigues (2021, p. 154),

[...] a realidade vivenciada pelos estudantes no ambiente escolar de institutos federais, majoritariamente adolescente, é transversalizada pelos mais variados contextos de vida, estando sujeitos a uma série de riscos vinculados à necessidade de aceitação por grupos de amigos, ao desejo de experimentar diferentes comportamentos, à sensação de onipotência, grandes mudanças corporais, além do início do envolvimento afetivo, do aumento da impulsividade e da busca de sensações novas, a execução de ações de promoção à saúde torna-se imprescindível com a finalidade não apenas de assegurar seu êxito na formação e sua permanência escolar, mas também como mecanismo para favorecer sua qualidade de vida global.

Por essas características e determinantes, compreende-se que as demandas de atendimento em saúde apresentadas ao/a assistente social no IFFluminense precisam ser sistematizadas e consolidadas por meio de um projeto de intervenção específico visto que a Política de Educação pode se tornar espaço privilegiado para a construção de saberes e práticas de saúde que promovam o bem estar e a qualidade de vida dos sujeitos.

Nesse sentido, a sistematização da atuação profissional frente a essa demanda e dentro da Política de Educação pode apontar estratégias profissionais exitosas, indicar pistas de caminhos a seguir e revelar possibilidades profissionais pouco exploradas. Os dados apresentados a seguir poderão advir chaves de análise dessa realidade profissional.

\section{Demandas de atendimento em saúde: construções do Serviço Social no IFFluminense}

A atuação profissional dos/as assistentes sociais no IFFluminense, assim como na maioria das Universidades e Institutos Federais, encontra-se no âmbito do Programa de Assistência Estudantil, especialmente no que se refere à concessão e gerenciamento de benefícios e em setores de atendimento ao estudante. Nesse sentido, o contato profissional com os estudantes, seja na realização de estudos socioeconômicos para fins de concessão de benefícios, seja no atendimento direto, revela demandas para além das necessidades materiais e pedagógicas. Dentre elas, as demandas por atendimento em saúde por parte dos estudantes.

O presente estudo teve como base as inquietações dos profissionais, autores deste capítulo, assistentes sociais do IFFluminense em três diferentes campi. A observação da existência 
de demandas de atendimento em saúde e a discussão sobre essas demandas, suscitaram a necessidade de pesquisar e sistematizar as ações e procedimentos realizados por esses profissionais.

Dessa maneira, o presente trabalho foi elaborado a partir de pesquisa bibliográfica e consulta documental e por meio de um levantamento realizado com os/as assistentes sociais em exercício no IFFluminense nos seus diversos campi e na Reitoria, buscando sistematizar o trabalho profissional referente às demandas de atendimento em saúde.

A pesquisa realizada com os/as assistentes sociais do IFFluminense ocorreu por meio de um questionário elaborado na plataforma Google Forms e disponibilizado a todos/as os/as profissionais em exercício no IFFluminense pelo e-mail institucional do FASIFF - Fórum de Assistentes Sociais do IFFluminense - que gera o envio automático a todos/as profissionais de Serviço Social que atuam nos campi e na Reitoria. Também foi encaminhado para o grupo de Whats App dos/as profissionais, acompanhado por um breve texto informando sobre a pesquisa. O questionário foi disponibilizado no mês de maio de 2021. Dentre os/as 16 assistentes sociais em exercício no IFFluminense, obteve-se a resposta de 10 profissionais.

O questionário foi composto por 24 perguntas, sendo 16 questões objetivas e 8 questões discursivas que tinham como objetivo complementar as questões objetivas. As questões elaboradas versaram sobre as demandas de atendimento em saúde por parte dos estudantes que chegam aos/as assistentes sociais no seu trabalho, abordando as formas de identificação dessas demandas, os níveis de atuação profissional, a percepção do/a profissional quanto o grau de recorrência e de intensidade de demandas e os procedimentos adotados pelos/as profissionais.

Sendo assim, foi possível classificar as questões apresentadas em 4 aspectos do trabalho profissional: a) aspectos estruturais e organização do trabalho institucional, b) aspectos processuais das demandas, c) procedimentos e instrumentos utilizados no atendimento, e d) trabalho e educação em saúde.

\subsection{Aspectos estruturais e organização do trabalho institucional}

Em relação aos aspectos estruturais e de organização do trabalho, foram formuladas questões sobre o setor de atuação do/a assistente social, a qual diretoria o setor está vinculado no organograma, quais profissionais compõem a sua equipe e se o profissional atua em outros setores ou projetos dentro da instituição além do qual está vinculado.

Foi possível verificar que todos/as os/as respondentes atuam em setores responsáveis pelo desenvolvimento da assistência estudantil ou pelo atendimento ao estudante, variando a nomenclatura dos setores (coordenação, núcleo ou diretoria). Um participante respondeu que atua no NAPNEE (Núcleo de Atendimento a Pessoas com Necessidades Educacionais Específicas), que é outro setor de atendimento ao estudante, outro atua na Coordenação de Qualidade de Vida, que também é responsável pela assistência estudantil e atendimento ao estudante, e outro atua na Coordenação de Políticas Estudantis da Reitoria, que se configura como um setor de gestão dessa política na instituição.

Considerando a vinculação do setor de atuação profissional no organograma institucional, 5 setores estão vinculados a uma diretoria própria de Assistência Estudantil ou Política Estudantil, 3 estão ligados a uma diretoria de Ensino ou de Ensino e Assistência Estudantil, 1 está vinculado a uma diretoria de Pesquisa, Extensão e Políticas Estudantis e 1 vinculado à Diretoria de Qualidade de Vida e Gestão de Pessoas. 
A composição das equipes desses setores varia de acordo com o campus de lotação, mas verifica-se que dentre os 10 respondentes, 8 trabalham com um profissional nutricionista, 6 com psicólogo, 4 com pedagogo, 4 com técnico em enfermagem, 3 com técnico em assuntos educacionais, $3 \mathrm{com}$ auxiliar ou assistente em administração, 2 com assistente de alunos, 2 com intérprete de libras, 1 com médico e 1 com "outros profissionais de saúde".

Conforme descrito acima, a maior parte dos/as respondentes integra a equipe com a presença de outros profissionais da área de saúde, sendo a presença mais marcante dos profissionais de nutrição e de psicologia, sendo expressiva também a presença de técnicos de enfermagem na equipe. É possível inferir que a presença de outros profissionais de saúde no setor de trabalho pode influenciar na apresentação e/ou identificação de demandas de atendimento de saúde por parte dos estudantes, uma vez que o setor passa a ser reconhecido pelos profissionais que o compõem.

Além da questão sobre a composição da equipe, foi formulada uma questão sobre a existência de um setor específico de saúde no campus de atuação do/a Assistente Social, pois a existência desse setor específico poderia representar uma convergência das demandas de atendimento em saúde, diminuindo a busca por esse atendimento no setor de lotação do/a Assistente Social ou aumentando a procura nos casos em que o setor de saúde esteja vinculado ao setor de assistência estudantil. Nesse aspecto, 7 respondentes informaram que existe um setor de saúde específico no seu campus de atuação e o respondente que trabalha na Reitoria mencionou a existência de um setor saúde, mas que não presta atendimento ao estudante. Tendo em vista que alguns/as assistentes sociais têm em sua equipe a presença de técnicos de enfermagem e médico, é possível inferir que, nesses casos, o setor de saúde encontra-se vinculado ao de assistência estudantil e essa estrutura propicia que a demanda por atendimento em saúde chegue até o/a assistente social.

Ainda sobre a organização do trabalho na estrutura organizacional, foi possível identificar que além de atuar no seu setor de lotação, os/as assistentes sociais também exercem atividades em outros setores ou projetos institucionais. Além do respondente que afirmou estar lotado no NAPNEE, outros/as 6 assistentes sociais afirmam atuar também nesse núcleo. Além disso, 6 profissionais informaram que atuam ou atuaram em projetos de pesquisa ou extensão e em comissões ou grupos de trabalho com temáticas específicas, como referentes à carreira, avaliação institucional e conselho de classe. Um dos respondentes afirmou estar participando no momento de projeto de extensão sobre saúde mental.

\subsection{Aspectos processuais das demandas}

No que se refere aos aspectos processuais das demandas de atendimento em saúde foram propostas perguntas relacionadas ao recebimento desse tipo de demanda pelo/a assistente social nos últimos 3 anos antes da Pandemia de Covid-19. Essa delimitação temporal foi necessária, visto que a organização do trabalho foi alterada a partir da implementação do trabalho remoto. Nesse sentido, as questões apresentadas tinham por objetivo identificar como essa demanda se apresenta ou é identificada, o grau de recorrência e o nível de atuação profissional que a demanda exige.

Dentre os/as 10 assistentes sociais participantes, 9 responderam que recebem demandas de atendimento em saúde por parte dos estudantes. Um participante, com lotação na Reitoria, respondeu que não recebe essa demanda, por esse motivo, as questões apresentadas a seguir, 
referentes a origem e recorrência da demanda foram indicadas por esse participante como baixa ou nula recorrência.

Em relação à origem da demanda - classificadas como Espontânea, Encaminhada, Programada ou Observada - e a sua recorrência - numa escala onde 0 (zero) significa menos recorrente e 5 (cinco) significa mais recorrente -, observa-se que a maior recorrência (recorrência igual ou maior que 3) encontram-se as demandas Encaminhadas (8 respostas) e as demandas Espontâneas (7 respostas). As demandas Observadas (casos em que o/a Assistente Social tenha identificado a demanda por meio do processo de estudo socioeconômico, busca ativa, participação em projeto, etc.) foram apontadas com maior recorrência por 6 participantes e as demandas Programadas (casos em que o atendimento estava previsto na organização do setor, como acompanhamento, por exemplo) foram indicadas como muito recorrentes por 5 participantes.

Embora a relação entre origem e a recorrência da demanda não tenha grande variação, compreende-se que esse tipo de demanda chega ao/a assistente social no seu cotidiano de trabalho como uma demanda para o setor de atendimento ao estudante, visto que outros setores e profissionais da escola não se sentem preparados para lidar com ela. É possível observar também que a menor recorrência de demandas espontâneas se encontra nos campi em que há setor de saúde específico. Por outro lado, há outros 4 casos em que mesmo com a presença do setor de saúde, há grande recorrência de demandas espontâneas para o/a assistente social. Nesses casos, é possível inferir que as equipes estão vinculadas ao mesmo setor ou estrutura organizacional, influenciando na chegada dessas demandas.

Especificamente sobre as demandas encaminhadas, os/as profissionais participantes indicaram que geralmente recebem a demanda dos coordenadores de curso, professores, direção de ensino, equipe pedagógica e direção de assistência estudantil. Há relatos também de colegas ou responsáveis pelo estudante que procuram o/a assistente social, buscando orientação em relação a alguma situação de saúde do estudante. Encaminhamentos por órgão ou profissional externo são praticamente inexistentes.

No que diz respeito ao tipo ou forma como a demanda se apresenta, foram propostas 17 situações, abrangendo situações de acidente no ambiente escolar, mal estar físico, outros problemas de saúde física, tipos de violência, questões de saúde mental e transtornos de aprendizagem. Destacam-se, para as análises deste trabalho, as situações apontadas com recorrência igual ou maior que 3 e indicadas por 5 ou mais profissionais respondentes.

Sendo assim, considerando as demandas espontâneas, encaminhadas, programadas ou observadas, verificam-se como mais recorrentes as seguintes situações: 1. Sintomas Indicativos de Crise de ansiedade em ambiente escolar (9 respostas); 2. Depressão (8 respostas); 3. Sintomas indicativos de Crise do Pânico em ambiente escolar (7 respostas); 4. Ideação suicida/tentativa de suicídio (7 respostas, mas grau menos frequente que a situação anterior); 5 . Violência psicológica em ambiente escolar (6 respostas); 6. Transtornos de Aprendizagem (6 respostas); 7. Outras questões relacionadas à saúde mental (5 respostas); 8 . Autolesão (5 respostas).

Além das opções propostas na questão fechada, foi possível os/as participantes indicarem outras situações que requerem atendimento em saúde. Dessa forma, foram mencionadas situações como violência moral e sexual, necessidade de atendimento ginecológico, IST's (Infecções Sexualmente Transmissíveis) e uso de bebidas alcóolicas, antidepressivos não receitados e outras drogas. Chama a atenção que as situações mais recorrentes que demandam 
atendimento em saúde por parte dos estudantes, em sua maioria, adolescentes e jovens adultos, são questões relacionadas à saúde mental.

\subsection{Procedimentos e instrumentos utilizados no atendimento}

No intuito de verificar os procedimentos e instrumentos utilizados pelo/a assistente social ao lidar com as demandas de atendimento em saúde, foram apresentadas questões referentes ao nível de atuação que a demanda exige, os procedimentos adotados e a forma de registro desse atendimento.

Dentre os níveis de atuação exigidos pelas demandas apresentadas (Assistência Imediata, Orientação/Mediação/Encaminhamento ou Educação em Saúde) relacionados à recorrência numa escala onde 0 (zero) significa menos recorrente e 5 (cinco) significa mais recorrente -, observa-se que a maior recorrência (recorrência igual ou maior que 3), indicada por 9 profissionais participantes, encontra-se no nível de "Orientação/Mediação/Encaminhamento", no qual o/a profissional atua na orientação ao estudante e à família e realiza encaminhamento para atendimento especializado.

O nível de "Assistência Imediata", no qual o estudante apresenta necessidade de assistência especializada em saúde imediata, como encaminhamento para serviços de urgência e emergência ou contato com familiares para providenciar o atendimento, foi indicado como muito recorrente por 4 profissionais. Por outro lado, 3 participantes indicaram que essa situação é pouco recorrente e 3 responderam que não realizam esse atendimento.

Em relação ao nível de atuação "Educação em Saúde", que compreende a realização e promoção de campanhas, palestras, material informativo, eventos e grupos com estudantes, 3 profissionais indicaram que atuam nesse nível com maior frequência, 6 indicaram que atuam nesse nível com menor frequência e 1 não realiza essa ação. Mediante a essa resposta, considerase como hipótese que os/as profissionais encontram dificuldades para atuarem em ações programadas e/ou planejadas em temas referentes à saúde, seja por estarem atuando em outras frentes, seja por não reconhecerem essa atividade como uma atividade profissional do/a assistente social.

Os procedimentos utilizados pelos/as profissionais ao lidarem com esse tipo de demanda foram levantados por meio de uma questão em que se apresentaram 7 opções de procedimentos e a opção “outros". Nessa questão, todos os procedimentos listados foram marcados como recorrentes (recorrência igual ou maior que 3). São eles: a) Contato com professores, coordenadores e/ou outros profissionais que lidam com o estudante ( 9 respostas); b) Atendimento ao Estudante (8 respostas) c) Estudo de caso e acompanhamento com a equipe de Assistência Estudantil (8 respostas); d) Encaminhamento externo para profissionais ou rede de saúde (7 respostas); e) Contato com familiares do estudante (7 respostas); f) Contato com a rede de serviço externa (7 respostas); g) Encaminhamento para outros setores, serviços ou profissionais da instituição (5 respostas). A opção "outros" foi indicada como não recorrente para 8 participantes e baixa recorrência para 2.

Os profissionais participantes indicaram que registram os atendimentos e procedimentos realizados, referentes às demandas de atendimento em saúde, em instrumentos próprios ou pelo SUAP (Sistema Unificado de Administração Pública). A maioria (7 participantes) realiza o registro "sempre" em instrumentos próprios. Apenas 1 participante realiza os registros "sempre" 
no SUAP, 5 registram "às vezes" neste instrumento e 4 não utilizam o SUAP para realizar registros.

\subsection{Trabalho e educação em saúde}

Observando a origem das demandas de atendimento em saúde apresentadas ao/a Assistente Social, os níveis de atuação profissional exigidos e as possibilidades de trabalho com os estudantes, a dimensão do trabalho com educação em saúde mostra-se uma estratégia de atuação importante. Mesmo que o uso dessa ferramenta tenha sido indicada como de menor recorrência entre os/as participantes, fica evidente que os/as profissionais pesquisados/as a consideram como uma possibilidade de trabalho.

Nesse sentido, uma das questões propostas buscou levantar quais ações de Educação em Saúde o/a assistente social havia desenvolvido como proponente ou colaborador/a. Foram apresentadas 5 opções de atividades e os/as respondentes podiam marcar mais de uma opção. Além disso, havia a opção “outros”, na qual o/a participante poderia descrever a ação. Todos/as os/as profissionais indicaram terem participado de alguma ação desse tipo. Em ordem de maior recorrência, encontra-se: a) Eventos (palestra, seminário, conferência, encontro, minicursos, workshop, etc.) - 9 respostas; b) Reunião com alunos e/ou turmas - 7 respostas; c) Campanha informativa sobre assunto específico - 6 respostas; d) Proferir palestra ou debate de algum tema relacionado à saúde do estudante - 4 respostas; e) Elaboração de material informativo sobre algum tema relacionado à saúde do estudante - 2 respostas. Além disso, dois/uas profissionais indicaram terem realizado projetos específicos sobre educação em saúde no IFFluminense ou em outra instituição de trabalho.

Os/as profissionais apontaram também o desenvolvimento de projetos como proponentes ou colaboradores/as em relação às demandas de atendimento em saúde dos estudantes. Dentre eles, destacam-se parcerias com órgãos públicos e privados para atendimento psicológico ao estudante, realização de palestras e rodas de conversa sobre saúde mental; projeto sobre alimentação e nutrição com a participação de nutricionista do campus; projeto sobre saúde mental na escola; realização de cursos, seminários e palestras sobre diversos temas de saúde, como IST's e direitos relacionados à saúde; distribuição de material e murais informativos; realização do "Dia da Saúde" com ações de aferição de pressão arterial, peso e altura e palestra sobre temas específicos em parceria com outros profissionais.

Por fim, os/as participantes indicaram temas e ações que deveriam ser trabalhados na instituição escolar na perspectiva de Educação em Saúde. Nesse sentido, os/as assistentes sociais mencionaram: necessidade de mais profissionais para trabalhar nessa frente de trabalho; a potencialização de trabalho na perspectiva de uma saúde que integre bem estar físico, mental e social; a necessidade de maior suporte à saúde mental dos estudantes; capacitação dos profissionais da educação para lidarem com as questões de saúde dos estudantes; educação popular em saúde; abordagens e projetos coletivos sobre saúde mental e escola; pesquisas e mapeamentos amplos sobre o assunto com o público estudantil; prevenção ao suicídio, violência doméstica e gravidez na adolescência; e desenvolver o conceito de humanização na instituição escolar. 


\section{Considerações finais}

O exercício de sistematizar as demandas de atendimento em saúde que chegam ao/a assistente social do IFFluminense e a realização do levantamento desse trabalho junto aos/as profissionais que atuam nessa instituição, permitiu construir reflexões sobre o assunto que, muitas vezes, ficam sobrepostas no cotidiano profissional e não são sistematizadas, tendo em vista que a requisição primordial nesse espaço funcional é a concessão e gerenciamento de benefícios de assistência estudantil.

O trabalho do/a Assistente Social na Política de Educação adquire dimensões de atuação que perpassam por ações que visam garantir o acesso e a permanência na educação escolarizada, a qualidade da educação e a gestão democrática dessa política (CFESS, 2012). Todas essas dimensões de atuação não podem estar descoladas das dimensões política e ideológica que embasam o projeto ético-político hegemônico da categoria. Emerge dessas dimensões, então, a possibilidade de trabalhar diversas demandas do corpo estudantil. Talvez seja daí, e do compromisso ético-político profissional, que surjam o reconhecimento das demandas de atendimento em saúde dos estudantes dentro da política de educação.

Esse reconhecimento não está dado e não deixa de representar um desafio no cotidiano profissional. É possível identificar limites e possibilidades de trabalho relacionados a essa demanda, que não pode ser compreendida como exclusiva dos profissionais de saúde e de atendimento ao estudante presentes na instituição. As barreiras na interlocução com os órgãos e profissionais externos, integrantes da rede pública de saúde, se configuram como limite de atuação, visto que dela depende o atendimento especializado e que nem sempre há oferta suficiente de atendimento ou articulação com a instituição mediante a diferença entre os entes federados, ou seja, IFFluminense (esfera federal) e a rede Municipal ou Estadual de saúde.

Por outro lado, há possibilidades de trabalho, tendo em vista que a educação escolarizada pode ser compreendida como promotora de saúde e como espaço privilegiado de educação em saúde. O envolvimento de toda a instituição educacional - docentes, técnicos, estudantes e familiares - pode revelar um caminho fecundo na educação em saúde, na elevação da saúde da população a médio e longo prazo e na melhoria da qualidade de vida em geral.

Por fim, esse estudo e as reflexões apresentadas aqui se configuram como uma modesta e inicial contribuição nesse debate. A discussão sobre o trabalho profissional nas diversas políticas e âmbitos de atuação requerem estudos permanentes e aprofundados, por isso, é necessário continuar o diálogo com a categoria profissional e os pesquisadores. Pode-se levantar questões, por exemplo, sobre a articulação do trabalho profissional nas políticas de Educação e de Saúde, a efetividade dos procedimentos adotados no atendimento dessas demandas, os caminhos mais fecundos em relação à prevenção e educação em saúde.

\section{Referências}

ABREU, E. M. C. de. O serviço social na educação profissional e tecnológica: as particularidades do exercício profissional dos/as Assistentes Sociais nos Institutos Federais de Educação. 2017. 278 p. Tese (Doutorado em Políticas Públicas) - Universidade Federal do Maranhão, São Luís, 2017. 
ABREU, E. M. C. de. O trabalho dos Assistentes Sociais na Educação Profissional e Tecnológica: as ações desenvolvidas no cotidiano profissional. In: XVI ENCONTRO NACIONAL DE PESQUISADORES EM SERVIÇO SOCIAL. 16, 2018, Vitória, Anais..., Vitória, Universidade Federal do Espírito Santo, 2018.

BLEICHER, T.; OLIVEIRA, R. C. N. de. Políticas de assistência estudantil em saúde nos institutos e universidades federais. Psicol. Esc. Educ. [online]. 2016, v. 20, n. 3, pp.543-549.

CHÁVEZ, G.M. et al. Teorização da demanda por profissionais e usuários da estratégia saúde da família: espontânea, programada, reprimida. Texto Contexto Enferm [Internet]. 29:e20180331, 2020. Disponível em: https://doi.org/10.1590/1980-265X-TCE-2018-0331. Acesso em: 05 jun 2021.

BRASIL. Lei $\mathbf{n}^{\mathbf{0}} \mathbf{1 1 . 1 9 5}$, de 18 de novembro de 2005. Dá nova redação ao $\int 5^{\circ}$ do art. $3^{\circ}$ da Lei no 8.948, de 8 de dezembro de 1994. Brasília, DF: Presidência da República, [2005]. Disponível em: http://www.planalto.gov.br/ccivil_03/_ato2004-2006/2005/lei/111195.htm. Acesso em: 10 jun. 2021.

BRASIL. Decreto $\mathbf{n}^{\mathbf{0}} \mathbf{6 . 0 9 6}$ de 24 de abril de 2007. Institui o Programa de Apoio a Planos de Reestruturação e Expansão das Universidades Federais - REUNI. Brasília, DF: Presidência da República, [2007] Disponível em: http://www.planalto.gov.br/ccivil_03/_ato20072010/2007/decreto/d6096.htm. Acesso em: 08 jun. 2021.

BRASIL. Lei n. ${ }^{\circ}$ 11.892, de 29 de dezembro de 2008. Institui a Rede Federal de Educação Profissional, Científica e Tecnológica, cria os Institutos Federais de Educação, Ciência e Tecnologia, e dá outras providências. Brasília, DF: Presidência da República, [2013]. Disponível em: http://www.planalto.gov.br/ccivil_03/_Ato2007-2010/2008/ Lei/L11892.htm. Acesso em: 01 maio 2021.

BRASIL. Decreto n. ${ }^{\mathbf{7} .234}$, de 19 de julho de 2010. Dispõe sobre o Programa Nacional de Assistência Estudantil. Brasília, DF: Presidência da República [2010]. Disponível em: http://www.planalto.gov.br/ccivil_03/_ato2007-2010/2010/decreto/d7234.htm. Acesso em: 03 maio 2021.

BRASIL. Lei 12.711, de 29 de agosto de 2012. Dispõe sobre o ingresso nas universidades federais e nas instituições federais de ensino técnico de nível médio e dá outras providências. Brasília, DF: Presidência da República [2012]. Disponível em: http://www.planalto.gov.br/ccivil_03/_ato2011-2014/2012/lei/112711.htm. Acesso em: 10 jun. 2021.

CARVALHO, E. L.; BARRETO, J.; RODRIGUES, D. O desenvolvimento da extensão como estratégia de promoção à saúde no espaço escolar. In: CARVALHO, E. L.; DOS ANJOS, N. B. (org.). Assistência estudantil: as múltiplas interfaces [recurso eletrônico]. Curitiba: Appris, 1. ed., 2021. cap. 7, p. 153-171. 
CFESS. Conselho Federal de Serviço Social. Subsídios para a atuação dos assistentes sociais na política de educação. Brasília, DF: CFESS, 2012. (Série 3: Trabalho e projeto profissional nas políticas sociais).

FONAPRACE. V Pesquisa Nacional de Perfil Socioeconômico e Cultural dos (as) Graduandos (as) das IFES. Relatório Executivo. Uberlândia: 2019.

INSTITUTO FEDERAL FLUMINENSE. Conselho Superior. Resolução N. ${ }^{\mathbf{0}}$ 43, de 21 de dezembro de 2018. Aprova, ad referendum, o Plano de Desenvolvimento Institucional - PDI (2018-2022). Campos dos Goytacazes: Conselho Superior, 2018. Disponível em: https://portal1.iff.edu.br/desenvolvimento-institucional/planejamento-institucional/plano-dedesenvolvimento-institucional-pdi/pdi-2018-2022-com-resolucao-menor.pdf/view. Acesso em: 01 mai. 2021.

INSTITUTO FEDERAL FLUMINENSE. Conselho Superior. Resolução N. ${ }^{\mathbf{3}}$ 39, de 11 de março de 2016. Aprova, o Programa de Assistência Estudantil do Instituto Federal Fluminense. Campos dos Goytacazes: Conselho Superior, 2016. Disponível em: http://cdd.iff.edu.br/documentos/resolucoes/2016/resolucao-no-39-de-11-de-marco-de-2016. Acesso em: 01 mai. 2021.

PAULINO, J. A. Demanda espontânea x Demanda programada: lidando com a procura maior que a oferta. 2014. 25p. Trabalho de Conclusão de Curso (Especialização em Atenção Básica em Saúde da Família). Universidade Federal de Minas Gerais. Conselheiro Lafaiete. 2014.

PRADA, T.; GARCIA, M. L. T.. Perfil das assistentes sociais dos Institutos Federais de Educação, Ciência e Tecnologia do Brasil. Serviço Social \& Sociedade, p. 304-325, 2017.

PRADA, T. O Trabalho em Rede na Intervenção das Assistentes Sociais dos Institutos Federais de Educação, Ciência e Tecnologia. 2015. 210 p. Dissertação (Mestrado em Política Social). Universidade Federal do Espírito Santo - UFES, Vitória, 2015. 